\title{
Parameters of photic resetting of the circadian system of a diurnal rodent, the nile grass rat*
}

\author{
Parâmetros de foto-ajustamento de fase do sistema circadiano de um roedor diurno, \\ o rato campestre do Nilo
}

\author{
Roberto Refinetti
}

\begin{abstract}
Research on circadian rhythms has been hampered by the lack of a suitable rodent model with diurnal habits. The goal of this study was to characterize the parameters of photic entrainment of the circadian system of the Nile grass rat, a small rodent that can potentially serve as a model for the study of circadian rhythms in diurnal animals. The state of the circadian system was accessed through the rhythm of running-wheel activity and manipulated by photic stimulation (white light). The results indicated that the grass rat exhibits a robust rhythm of running-wheel activity with a mean free-running period of 23.9 hours (range: 23.6 to 24.3 hours). The animal is clearly diurnal and starts activity daily approximately 50 minutes before lights-on under an L12:D12 light-dark cycle. Its photic phase-response curve shows a dead zone during most of subjective day, a phase delay region during early subjective night (maximal delay: 1.5 hours), and a phase advance region during late subjective night (maximal advance: 2.2 hours). When exposed to constant illumination, the grass rat exhibits longer circadian periods as the intensity of illumination increases, with a ceiling between 100 and 1,000 lux. Finally, its range of entrainment extends from at least 23.0 to 25.0 hours (from 22.0 to 25.5 in some animals).
\end{abstract}

Key words: Arvicanthis niloticus, circadian rhythm, entrainment, locomotor activity.

\section{RESUMO}

O progresso da pesquisa sobre ritmos circadianos sofre pela ausência de um roedor diurno adequado para estudos de laboratório. O objetivo deste estudo foi o de caracterizar os parâmetros de foto-ajustamento de fase do sistema circadiano do rato campestre do Nilo, um roedor de pequeno porte que possui o potencial para servir de modelo para o estudo de ritmos circadianos em animais diurnos. O estado do sistema circadiano foi investigado através do ritmo de atividade em rodas de exercício e foi manipulado através de estimulação luminosa. Os resultados indicaram que o rato campestre exibe um ritmo de atividade robusto com um período em curso livre de 23,9 horas (limites: 23,6 a 24,3 horas). $\mathrm{O}$ animal é claramente diurno e inicia a atividade locomotora diariamente por volta de 50 minutos antes do acendimento das luzes quando é mantido sob um ciclo claro-escuro com12 horas de luz e 12 horas de escuridão. Sua curva de resposta dependente de fase possui uma zona morta durante a maior parte do dia subjetivo, uma região de atraso de fase durante o início da noite subjetiva (atraso máximo: 1,5 horas) e uma região de avanço de fase durante o fim da noite subjetiva (avanço máximo: 2,2 horas). Quando é exposto a iluminação constante, o rato campestre exibe períodos circadianos que se alongam à medida em que a intensidade da iluminação é aumentada, com um patamar superior entre 100 e 1.000 lux. Finalmente, os limites de arrastamento desta espécie são 23,0 e 25,0 horas (ou 22,0 a 25,5 horas em alguns animais).

Descritores: arrastamento de ritmo, Arvicanthis niloticus, atividade locomotora, ritmo circadiano. 


\section{INTRODUCTION}

The temporal niche of a species may be as important for survival as its geographical niche [2, 3]. Searching for food at a time of the day when predators abound and prey is scarce is unlikely to be an adaptive strategy. But how do animals establish their temporal niche? Although most mammals can be classified as either diurnal (day-active) or nocturnal (nightactive), little is known about why they occupy one temporal niche or the other.

From the perspective of circadian physiology, diurnality and nocturnality are expressions of the "phase angle of entrainment"- that is, they reflect the effects of photic stimulation on the daily resetting of the circadian clock $[6,12]$. However, it is still unclear whether the organization of the circadian system of the two groups is substantially different, as the phase-response curves relating phase shifts to the time of photic stimulation are very similar in the two groups $[1,5]$. On the other hand, diurnal animals in the wild are exposed to much greater intensities of light than nocturnal animals are, which may have significant effects on entrainment [4].

One reason for the lack of knowledge about differences in the circadian physiology of diurnal and nocturnal animals is the lack of appropriate models for laboratory studies. Most research on the entrainment of circadian rhythms has been conducted on nocturnal rodents [15]. Although studies have occasionally been conducted on small diurnal mammals [7, 8, 10, 11, 14], a good diurnal rodent has yet to be identified. The present article describes a series of studies of the parameters of photic resetting of the circadian system of the Nile grass rat (Arvicanthis niloticus), a small rodent from north Africa that has a predominantly diurnal pattern of activity [9].

\section{MATERIALS AND METHODS}

Grass rats were bred in the laboratory using three breeding pairs obtained from Dr. Laura Smale at Michigan State University. The animals were 4 months old at the beginning of the experiments and were fed Purina rodent chow (Lab Diet 5001) and water ad libitum throughout the study.

During the experiments, the animals were housed individually in polypropylene cages $(24 \times 36$ x
$19 \mathrm{~cm}$ ) lined with wood shavings. As is customary in circadian physiology [15], the state of the circadian system was accessed through the rhythm of runningwheel activity. A metallic running wheel $(15 \mathrm{~cm}$ diameter), containing a magnetic switch, was attached to each animal cage; each switch was connected to a data acquisition board ${ }^{1}$ plugged to a computer, which recorded the number of wheel revolutions in 6-min bins (i.e., $0.1 \mathrm{~h}$ intervals). The animal cages were maintained in individual light-tight, ventilated chambers at $24^{\circ} \mathrm{C}$.

Lighting conditions in each chamber were controlled by programmable electronic timers ${ }^{2}$ that activated white fluorescent bulbs (General Electric F4T5CW) generating an illuminance of approximately 360 lux (range: 340 to 390 lux across chambers), as measured $8 \mathrm{~cm}$ above the cage floor. When called for by the experimental protocol, regular pulses of white light were administered in each animal's own isolation chamber (360 lux) without physical disturbance of the animals. Changes in the intensity of light were attained by the use of neutral density filters.

Four experiments were conducted. In the first experiment, 50 animals (of both sexes) were exposed to a light-dark cycle (L12:D12) for four or more weeks so that their phase angles of entrainment could be determined. At the end of the experiment, the animals were placed under constant darkness so that their freerunning periods could be determined.

In Experiment 2, a phase-response curve was built using 54 animals. The animals were placed in constant darkness for two weeks and received a single light pulse (360 lux, 4-hour long) at the end of the first week. Different animals received the light pulse at different circadian times, so that approximately 2-3 data points were obtained for each circadian hour.

In Experiment 3, the effect of constant illumination on the free-running period was investigated. The animals $(\mathrm{N}=16)$ were maintained under constant illumination at 5 different levels $(0,0.1,1,10$, and 100 lux) for two or more weeks at each level. Half of the animals experienced an ascending order of illumination levels and half experienced a descending order.

In Experiment 4, the range of entrainment was investigated. The animals $(\mathrm{N}=18)$ were exposed to light-dark cycles of various periods (always with 8 
hours of light per cycle). Half of the animals was exposed to cycles with periods of 24.0, 23.5, 23.0, 22.5, and 22.0 hours (in this order) for two or more weeks at each cycle. The other half was exposed to cycles with periods of 24.0, 24.5, 25.0, 25.5, and 26.0 hours (in this order) for two or more weeks at each cycle.

Running wheel data were plotted as actograms, and circadian times were determined from the actograms using the daily onset of activity as circadian time zero (CT 0). Phase shifts were determined by drawing separate eye-fit lines through the onsets for 6 or 7 days before and 6 or 7 days after the pulse (discarding days with transients, if present) and calculating the time between the two lines on the first cycle following the pulse [13]. Determinations of circadian period were accomplished by the chi-square periodogram procedure [16].

\section{RESULTS}

Running-wheel activity records of a representative grass rat are shown in Figure 1. The records include two weeks under an L12:D12 cycle and four weeks in constant darkness. There is clear entrain- ment, with activity limited to the light phase of the light-dark cycle, followed by clear free-run with a period shorter than 24 hours (i.e., the onsets advance a few minutes each day). Not all animals exhibited such a robust activity rhythm in constant darkness.

Negative masking (i.e., sparse running-wheel activity) was observed in one out of eight animals, and the records of 4 out of 50 animals were so poor in constant darkness that no determination of free-running period was possible.

The frequency distribution of onset times for the 50 grass rats maintained under L12:D12 is shown in Figure 2. All animals started running a little before lightson each day. Most animals started running 40-60 min before lights-on. No animal started running more than $80 \mathrm{~min}$ or less than $20 \mathrm{~min}$ before lights-on.

The frequency distribution of free-running periods (in constant darkness) is shown in Figure 3. In the 46 animals whose records could be analyzed, circadian period ranged from 23.6 to 24.3 hours with a mean of 23.9 hours.

The phase-response curve depicting phase shifts as a function of circadian time is shown in Figure 4. Practically no shifts were observed from CT 0 to CT 8 ,

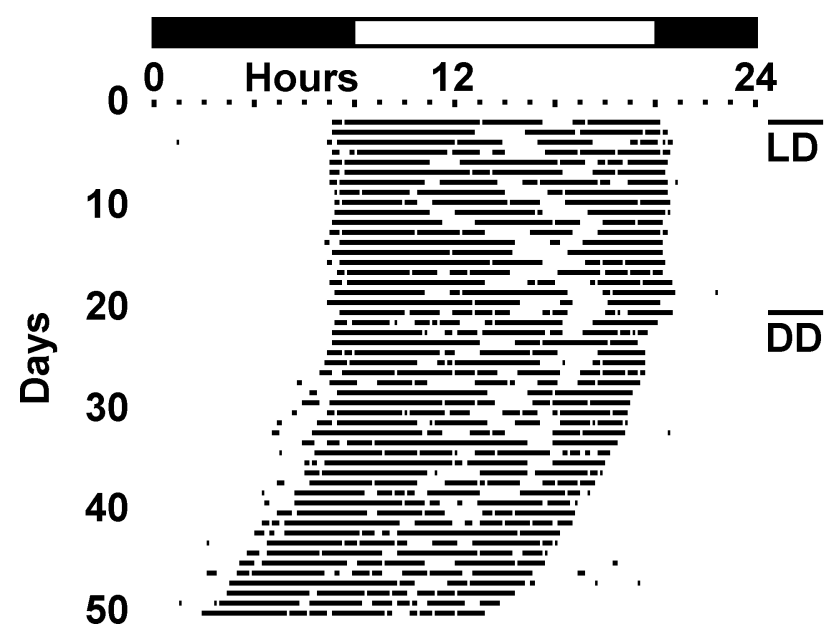

Figure 1. Actogram of the rhythm of running-wheel activity of a representative Nile grass rat maintained under an L12:D12 light-dark cycle (LD) for two weeks and in constant darkness (DD) for four weeks. In the actogram format, each line corresponds to a day, and successive lines correspond to successive days. For each 6-min bin, a pen deflection is present if there were one or more wheel revolutions; otherwise, the space is left blank. The horizontal bar at the top of the figure indicates the duration of the light and dark phases of the light-dark cycle (which was in effect for the first two weeks of the records). 
phase delays were observed from CT 8 to CT 18 , and phase advances were observed from CT 18 to CT 24. The fitted curve indicates a maximal phase delay of 1.5 hours and a maximal phase advance of 2.2 hours.
The mean results for the investigation of the effects of light intensity on circadian period (under constant illumination) are shown in Figure 5. The mean period lengthened from 23.9 hours at 0 lux to almost 24.6 hours at 100 lux. Although an asymptotic level

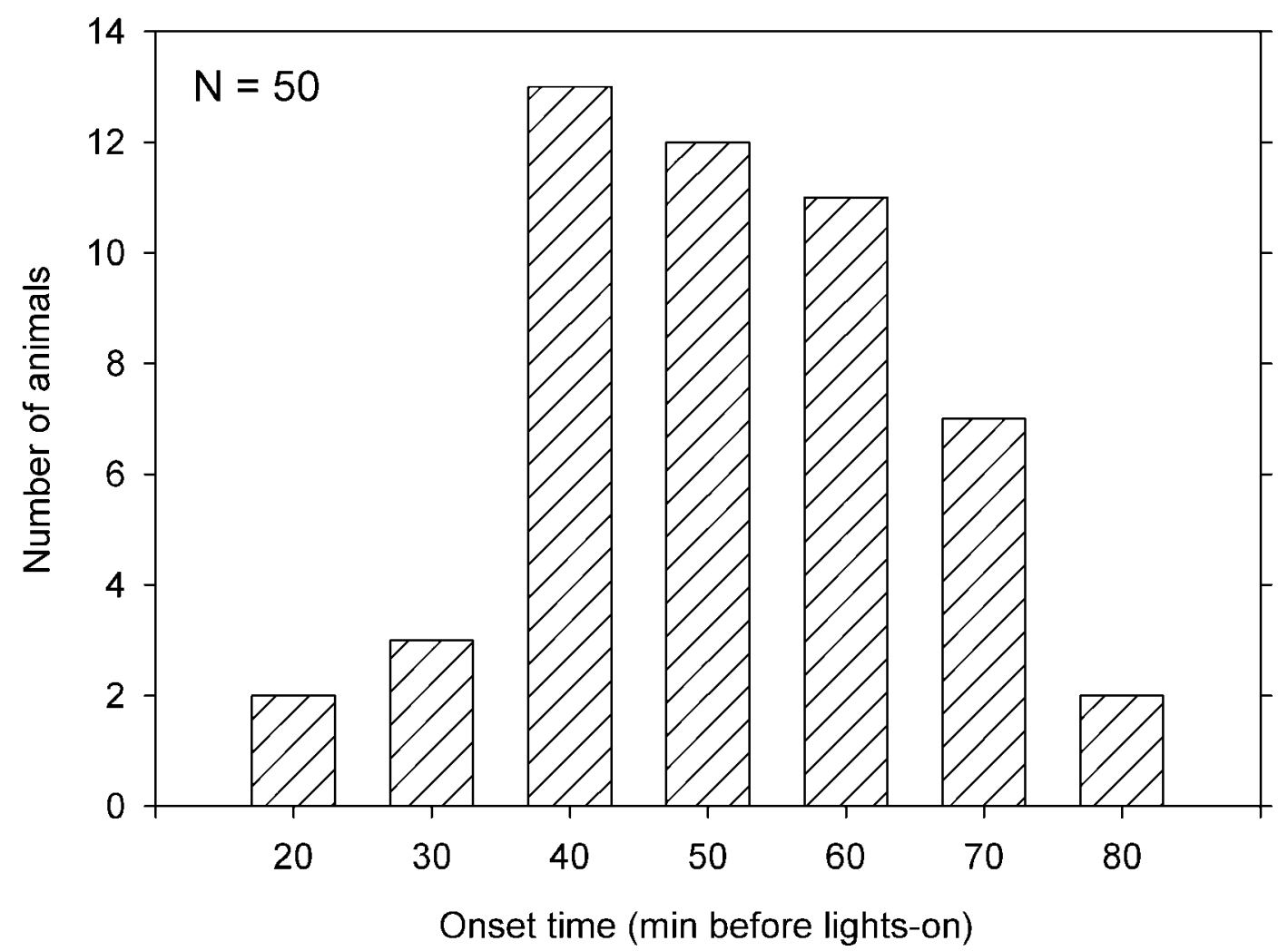

Figure 2. Frequency distribution of times of activity onset of 50 grass rats exposed to an L12:D12 light-dark cycle.

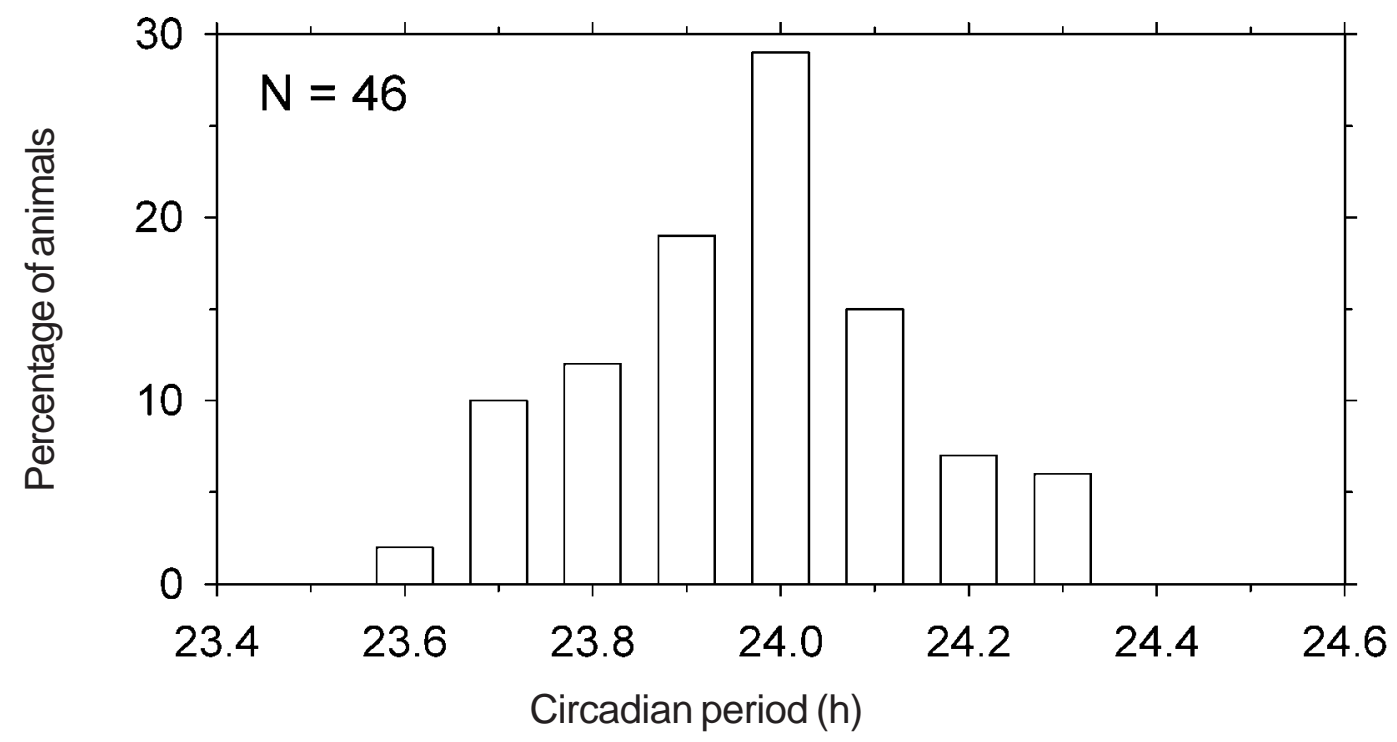

Figure 3. Frequency distribution of the free-running periods of 46 grass rats maintained in constant darkness 


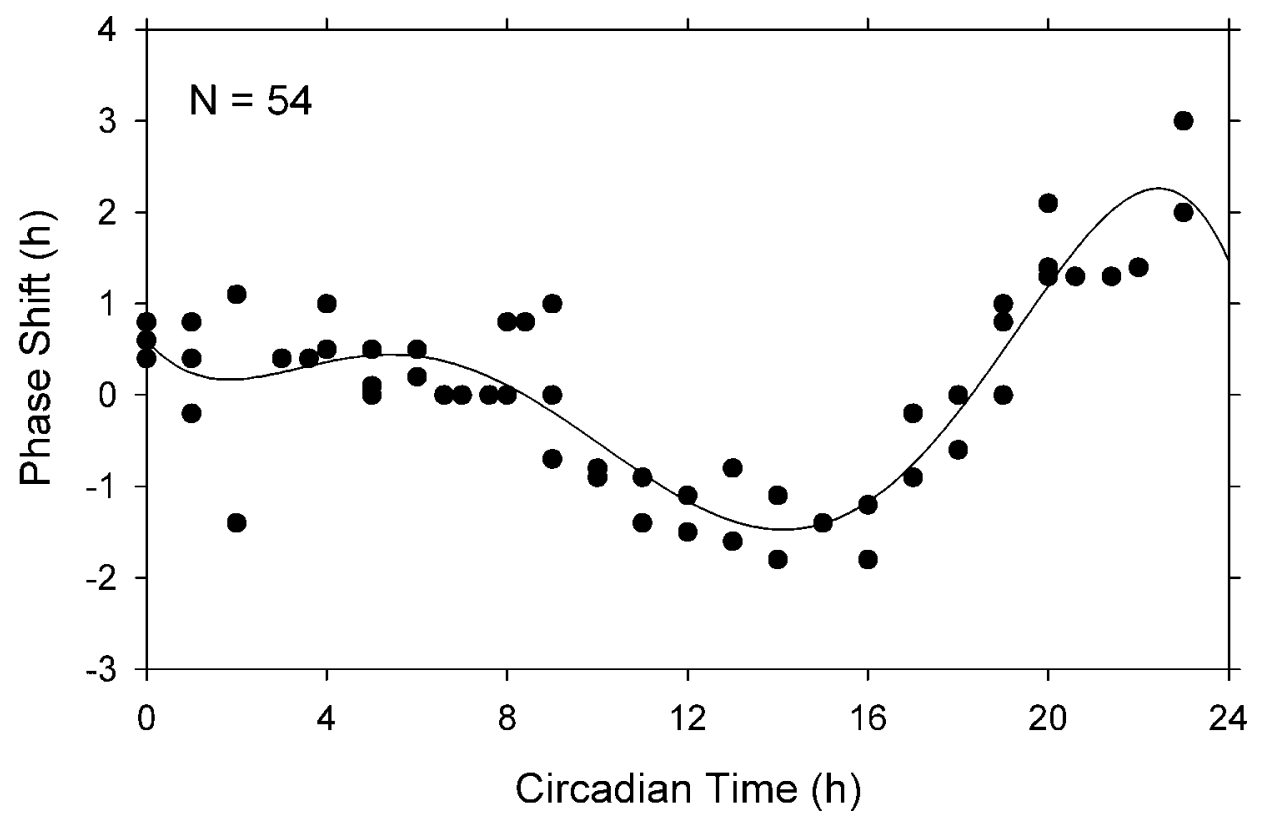

Figure 4. Phase-response curve depicting phase shifts evoked by single light pulses presented at different circadian times to grass rats maintained in constant darkness. By convention, phase delays are reported as negative shifts and phase advances as positive shifts. Circles denote individual phase shifts. The curve describes a $5^{\text {th }}$-order polynomial fitted by the principle of the least squares.

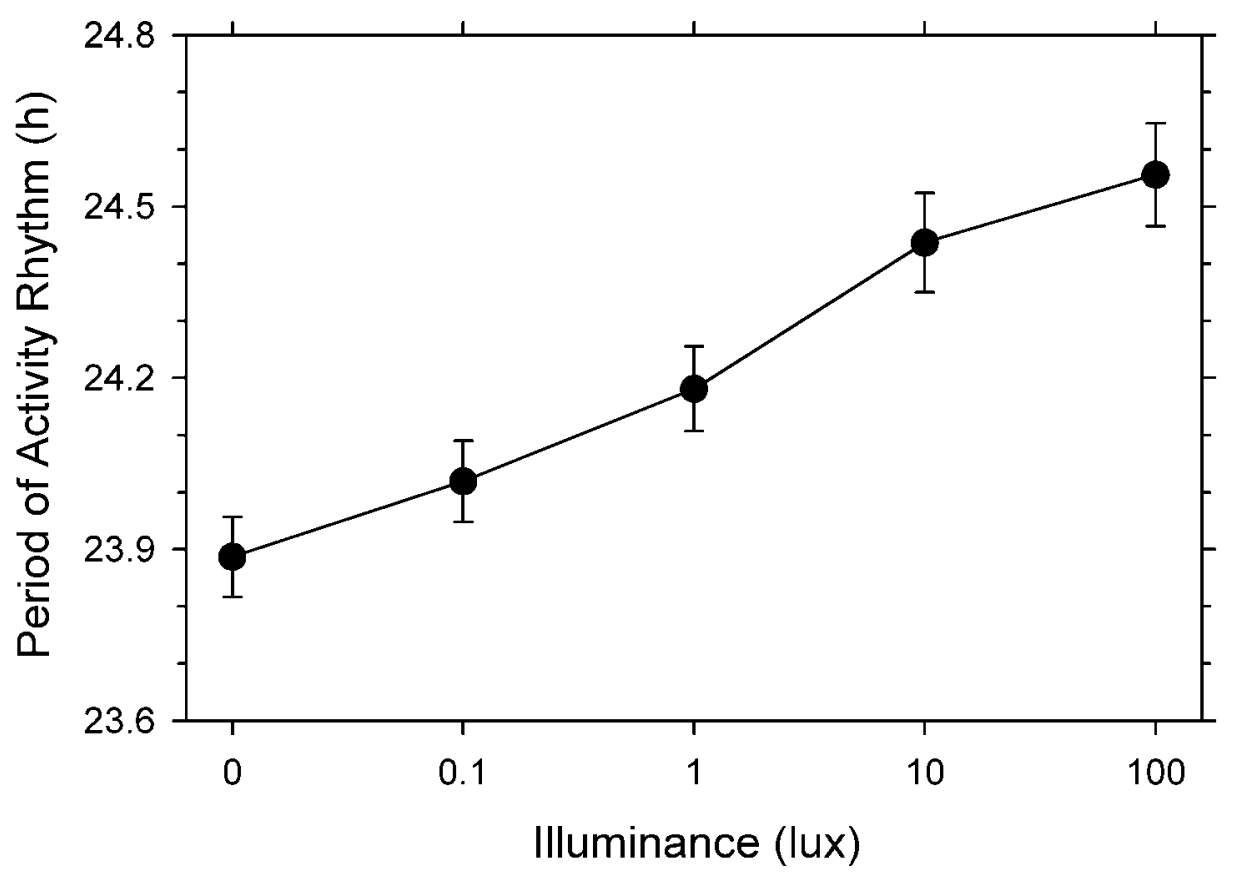

Figure 5. Period of the activity rhythm as a function of the intensity of constant illumination. Each point is the mean ( \pm SE) of 16 grass rats. Notice that the scale of the abscissa is logarithmic. The value of 0 lux has been arbitrarily placed at the position corresponding to 0.01 lux (as 0 has no logarithm). 


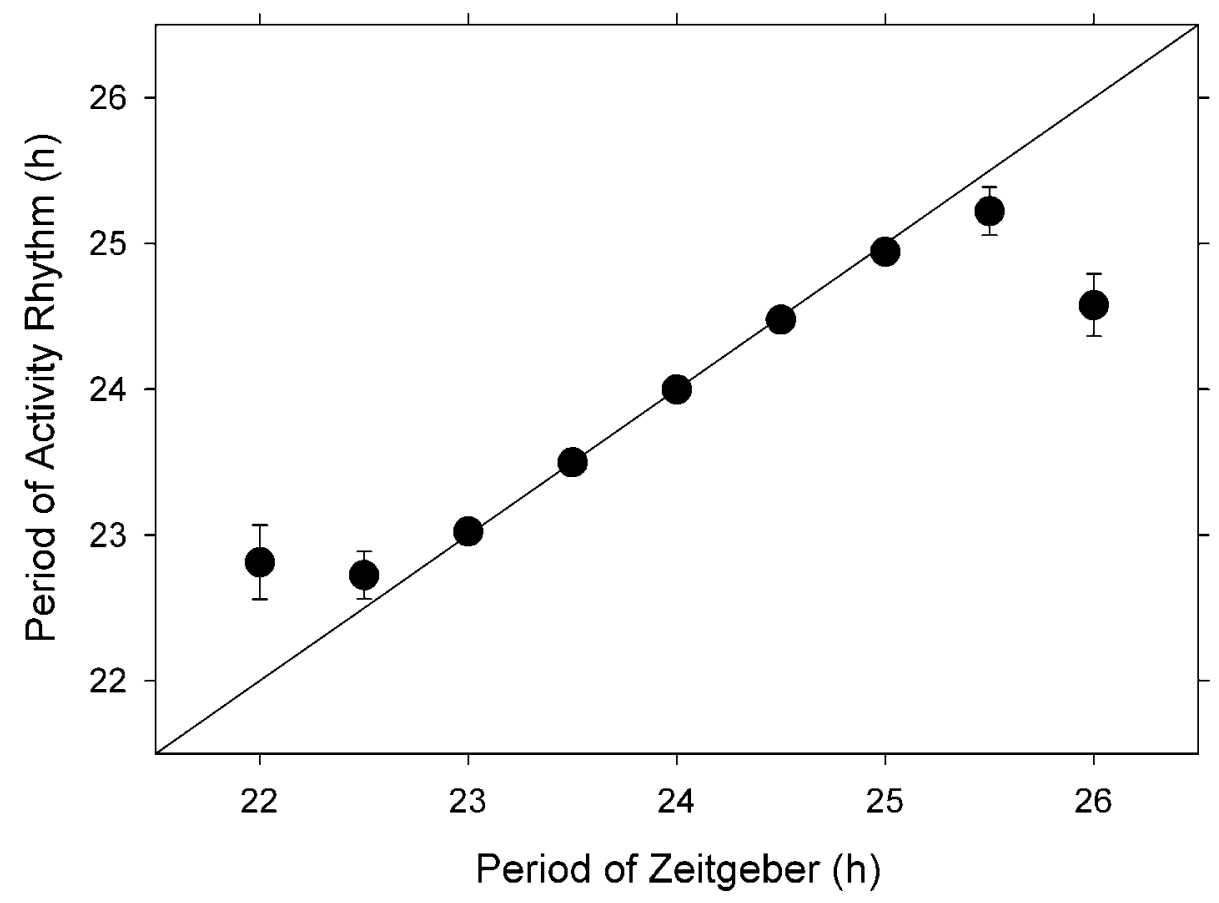

Figure 6. Period of the activity rhythm as a function of the period of the light-dark cycle (zeitgeber). Each point is the mean $( \pm$ SE) of 9 grass rats, except for 24.0 hours (where $n=18$ ). The line depicts equality of rhythm and zeitgeber periods.

was not clearly approached, the slope of the function seems to be reduced in the segment from 10 to 100 lux, suggesting that a maximal effect may be attained between 100 and 1,000 lux.

Finally, the mean results for the investigation of the range of entrainment are shown in Figure 6. It seems clear that entrainment was fully established for zeitgeber periods from 23.0 to 25.0 hours. For zeitgeber periods farther away from 24.0 hours, the period of the activity rhythm started to revert to the freerunning period of 23.9 hours, thus indicating a progressive loss of entrainment.

\section{DISCUSSION}

The results of this study provided a characterization of the parameters of photic entrainment of the circadian system of the Nile grass rat. This rodent exhibits a robust rhythm of running-wheel activity with a mean free-running period of 23.9 hours. It is clearly diurnal and starts activity daily approximately 50 minutes before lights-on under an L12:D12 light-dark cycle. Its photic phase-response curve shows a dead zone during most of subjective day, a phase delay region during early subjective night, and a phase advance region during late subjective night. When exposed to constant illumina- tion, it exhibits longer circadian periods as the intensity of illumination increases, with a ceiling between 100 and 1,000 lux. Finally, its range of entrainment extends from at least 23.0 to 25.0 hours.

These results are consistent with those obtained in previous studies in nocturnal and diurnal animals [15]. The grass rat's free-running period (23.9 hours) is slightly longer than that of the domestic mouse (23.6 hours) and slightly shorter than that of the laboratory rat (24.2 hours). Its phase angle of entrainment (onsets 50 minutes before lights-on) is consistent with its circadian period shorter than 24 hours and its photic phase-response curve (which requires phase control of light exposure at the end, not the beginning of subjective day). Its range of entrainment (23.0 to 25.0 hours in all animals, from 22.0 to 25.5 in some animals) is also consistent with the features of the phaseresponse curve (i.e., maximal delay of 1.5 hours and maximal advance of 2.2 hours). The modulation of circadian period by the intensity of constant light (longer periods at higher intensities) is not consistent with the features of the phase-response curve (greater advances than delays) but is similar to that exhibited by the nocturnal rodent most widely used in the study of photic entrainment — the golden hamster. 
The Nile grass rat has great potential as a model for the study of circadian rhythms in diurnal animals. Its robust rhythm of running-wheel activity adds to the value of the desirable characteristics of its circadian system. Its small size $(120 \mathrm{~g})$ and docile disposition are also valuable assets. It remains to be determinated if it reproduces well in captivity. In my laboratory, breeding was successful at first. Animals were easily mated, and couples maintained together produced a new litter of 4 to 7 pups every 21 days. More recently, however, infanticide and killing of the female by the male have been observed.
Several couples have been successfully kept together but yielded no litters. At this time, it is not clear why the initial success of the breeding program has been dwindling. Thus, the potential of the Nile grass rat as a model for the study of circadian rhythms in diurnal animals may be jeopardized by breeding difficulties.

\section{Sources and Manufacturers}

${ }^{1}$ Digital Input Card AR-B2001, Acrosser Technology, Taiwan.

${ }^{2}$ ChronTrol XT, ChronTrol Corp., San Diego, CA, USA.

\section{REFERENCES}

1 Aschoff J. 1965. Response curves in circadian periodicity. In: Aschoff J. (Ed). Circadian Clocks. Amsterdam: NorthHolland, pp. 95-111.

2 Daan S. 1981. Adaptive daily strategies in behavior. In: Aschoff J. (Ed). Biological Rhythms. New York: Plenum, pp. 275-298.

3 Horton T. H. 2001. Conceptual issues in the ecology and evolution of circadian rhythms. In: Takahashi J.S., Turek F.W. \& Moore R.Y. (Eds). Circadian Clocks. New York: Kluwer Academic, pp. 45-57.

4 Hut R.A., van Oort B.E.H. \& Daan, S. 1999. Natural entrainment without dawn and dusk: the case of the European ground squirrel (Spermophilus citellus). Journal of Biological Rhythms. 14: 290-299.

5 Johnson C.H. 1999. Forty years of PRCs: what have we learned? Chronobiology International. 16: 711-743.

6 Johnson C.H., Elliott J.A. \& Foster R. 2003. Entrainment of circadian programs. Chronobiology International. 20: 741-774.

7 Kas M.J. \& Edgar D.M. 2000. Photic phase response curve in Octodon degus: assessment as a function of activity phase preference. American Journal of Physiology. 278: R1385-R1389.

8 Labyak S.E., Lee T.M. \& Goel N. 1997. Rhythm chronotypes in a diurnal rodent, Octodon degus. American Journal of Physiology. 273: R1058-R1066.

9 McElhinny T.L., Smale L. \& Holekamp K.E. 1997. Patterns of body temperature, activity, and reproductive behavior in a tropical murid rodent, Arvicanthis niloticus. Physiology and Behavior. 62: 91-96.

10 Meijer J.H., Daan S., Overkamp G.J. \& Hermann P.M. 1990. The two-oscillator circadian system of tree shrews (Tupaia belangeri) and its response to light and dark pulses. Journal of Biological Rhythms. 5: 1-16.

11 Mrosovsky N., Edelstein K., Hastings M.H. \& Maywood E.S. 2001. Cycle of period gene expression in a diurnal mammal (Spermophilus tridecemlineatus): implications for nonphotic phase shifting. Journal of Biological Rhythms. 16: 471-478.

12 Pittendrigh C.S. 1981. Circadian systems: entrainment. In: Aschoff J. (Ed). Biological Rhythms. New York: Plenum, pp. 95-124.

13 Refinetti R. 1993. Comparison of six methods for the determination of the period of circadian rhythms. Physiology and Behavior. 54: 869-875.

14 Refinetti R. 1999. Relationship between the daily rhythms of locomotor activity and body temperature in eight mammalian species. American Journal of Physiology. 277: R1493-R1500.

15 Refinetti R. 2000. Circadian Physiology. Boca Raton: CRC Press, 184 p.

16 Sokolove P.G. \& Bushell W.N. 1978. The chi square periodogram: its utility for analysis of circadian rhythms. Journal of Theoretical Biology. 72: 131-160.

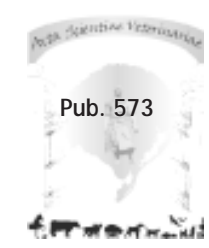

